\title{
Realidade e Diretrizes Oficiais da Educação em Química: Qual é a Distância?
}

\section{RESUMO}

Raul Ribeiro Jungles de Lima rauljungles@gmail.com

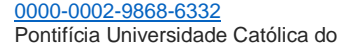
Paraná, Paraná, Brasil.

\section{Rodrigo Pedroso da Silva} pedroso201184@gmail.com 0000-0002-6057-9005 Universidade Tecnológica Federal do Paraná, Paraná, Brasil.

Daniel Schwanka Gbur danielsgbur@hotmail.com Pontifícia Universidade Católica do Paraná, Paraná, Brasil.

\section{Matheus Miranda Barboza} matrpg12@hotmail.com 0000-0003-4641-0462 Pontifícia Universidade Paraná, Paraná, Brasil.

Lays de Carvalho Seixas Costa laysdecarvalho@hotmail.com

0000-0002-0034-487X

Pontifícia Universidade Católica do

Paraná, Paraná, Brasil.

\begin{abstract}
Após a análise dos documentos oficias que guiam e asseguram a qualidade metodológica da educação brasileira, tornar-se claro quais devem ser as concepções que um aluno do ensino médio deve dominar em relação à química após a finalização, ou próximo disso, de seus estudos. A memorização de fórmulas e repetições pautadas em referenciais simbólicos visando o ensino de determinada especificidade, cederam espaço a uma aplicação interdisciplinar e contextualizada. Contudo, pautado em relatos de professores e observações realizadas durante dois anos de iniciação à docência (PIBID), nota-se uma divergência realmente significativa em relação ao que se espera, de acordo com os documentos, e o que é observado na realidade do ensino médio. Portanto, este projeto tem como objetivo constatar se essas observações estão de acordo com a realidade. Os resultados em relação ao aprendizado técnico/contextualizado em química são preocupantes, contudo, a perspectiva do aluno acerca desta situação é ainda mais intrigante.
\end{abstract}

PALAVRAS-CHAVE: Educação em química. Currículo e realidade. Eficiência ensinoaprendizagem. Problematização em química. 


\section{INTRODUÇÃO}

Os Parâmetros Curriculares Nacionais (PCN) (BRASIL, 1997) da área de Ciências da Natureza, Matemática e suas Tecnologias apresentam recomendações para área de Ensino Médio, em especial, como seguir com o desenvolvimento de habilidades que permitam ao estudante a compreensão do mundo em toda a sua complexidade e subjetividade, levando, então, a formação de um cidadão completo e consciente dos seus direitos (SOUZA, 2009, p.4). Especificamente, o documento assinala a representatividade da Química na sociedade atual em seus aspectos econômicos, sociais e políticos (CARVALHO, 2014, p.21; BRASIL, 1997).

Desenvolver a representação e comunicação; investigação e compreensão; e contextualização sociocultural, são um dos principais eixos temáticos de compreensão da Química em seu âmbito de maior complexidade apresentados pelos Parâmetros Curriculares Nacionais (PCN) (BRASIL, 1997, p.33).

Segundo Carvalho (2014, p.17), o PCN ainda sugere que o estudante desenvolva algumas competências que permitam a leitura do mundo pelo aluno com os olhos, por mais que básicos, da química, pois esta ciência utiliza uma linguagem própria em sua representação. Então para que o estudante compreenda seus símbolos e representações, é necessário que ele desenvolva algumas competências. Junto a isso, o PCN assegura que a memorização de formulas, repetição e práticas pobres de desenvolvimento do raciocínio lógico devem ser evitadas, procurando sempre trabalhar, em sala de aula, a contextualização, representação e problematização da química em seu contexto social (BRASIL, 2006, p.117).

Junto a isso, o PCN+ (BRASIL, 2002), documento complementar ao PCN e responsável por direcionar a prática docente em sala de aula, acrescenta alguns aspectos específicos que devem ser considerados, por exemplo, em relação as competências quais devem ser desenvolvidas:

\footnotetext{
As competências gerais a serem desenvolvidas na área de Ciências da Natureza, Matemática e suas Tecnologias dizem respeito aos domínios da representação e comunicação, envolvendo a leitura e interpretação de códigos, nomenclaturas e textos próprios da Química e da Ciência, a transposição entre diferentes formas de representação, a busca de informações, a produção e análise crítica de diferentes tipos de textos; da investigação e compreensão, ou seja, o uso de ideias, conceitos, leis, modelos e procedimentos científicos associados a essa disciplina; e da contextualização sociocultural, ou seja, a inserção do conhecimento disciplinar nos diferentes setores da sociedade, suas relações com os aspectos políticos, econômicos e sociais de cada época e com a tecnologia e cultura contemporâneas (BRASIL, 2002, p.88).
}

Junto a esses dois documentos, ainda se encontra as Orientações Curriculares Nacionais (BRASIL, 2006). Visando possibilitar o diálogo entre as áreas do conhecimento em Ciências Exatas e da Natureza, os componentes curriculares são organizados com a intenção de propiciar um ambiente potencial para práticas interdisciplinares e transdisciplinares abrindo espaço, também, para a correlação entre os professores e seus colegas da área (CARVALHO, 2014, p.25). Torna-se possível, então, de acordo com o documento, um ensino integrado que, segundo Taba $(1974$, p.71) tem o objetivo de atingir a realidade de que "tanto o leigo como o especialista do amanhã devem ter uma base suficientemente ampla para 
permitir tomar consciência sobre o que ocorre em um mundo tomado por estudos especializados.".

Em relação ao documento de contexto que permeia este projeto, as Diretrizes Curriculares da Educação Básica em Química do Estado do Paraná DCEPR (PARANÁ, 2008), que apresenta a estruturação teórica e condução dos temas para o professor, assegura também que:

\begin{abstract}
Os conteúdos disciplinares devem ser tratados, na escola, de modo contextualizado, estabelecendo-se, entre eles, relações interdisciplinares e colocando sob suspeita tanto a rigidez com que tradicionalmente se apresentam quanto o estatuto de verdade atemporal dado a eles. Desta perspectiva, propõe-se que tais conhecimentos contribuam para a crítica às contradições sociais, políticas e econômicas presentes nas estruturas da sociedade contemporânea e propiciem compreender a produção científica, a reflexão filosófica, a criação artística, nos contextos em que elas se constituem (PARANÁ, 2008, p.14)
\end{abstract}

Agora tratando-se da ferramenta de análise aqui aplicada, segundo Moraes e Galiazzi (2006, p. 132) a Análise Textual Discursiva (ATD) pode ser dividida em três grandes etapas de desenvolvimento, são elas: A unitarização, categorização e a captação do novo emergente. Em relação à unitarização, esta fase corresponde a leitura inicial do que se pretende analisar, onde há, neste momento, a desconstrução, pelo pesquisador, das categorias e subdivisões apresentadas gerando várias unidades significativas, isto é, várias informações fragmentadas e singulares. Na segunda etapa da análise, a categorização, é onde começa a se reorganizar o que se foi desorganizado e fragmentado na etapa de unitarização, agora, serão agrupadas as unidades significativas segregadas na primeira etapa.

Ainda segundo Moraes (2003, p. 197), a etapa de categorização não apresenta características lineares, isto é, é necessária a releitura de determinadas unidades e reagrupamento destas onde é mais conveniente e coerente, logo, para a etapa de categorização, são estabelecidos alguns critérios para garantir a uniformidade da categoria, são eles: validade ou pertinência, homogeneidade e não exclusão mútua. Após a finalização da elaboração das categorias, de acordo com Moraes (2003, p. 202), inicia-se a última etapa da análise textual discursiva, a de captação do novo emergente. Nessa fase, o pesquisador se esforça em expressar suas intuições e novos entendimentos a partir da sua rigorosa e ostensiva análise dos dados. A validade e confiabilidade dos resultados de uma análise, como exposto por Moraes (2003, p. 206), depende "do rigor com que cada etapa da análise foi construída" uma vez que de "uma unitarização e de uma categorização rigorosas encaminham para metatextos válidos e representativos dos fenômenos investigados".

Logo, após a realização de uma ATD dos documentos educacionais oficiais de acordo com o que foi exposto acima, tornar-se claro quais devem ser as concepções qual um aluno do ensino médio deve dominar em relação à química após a finalização, ou próximo disso, de seus estudos. Isto é, a memorização de fórmulas e repetições pautadas em referenciais simbólicos visando o ensino de determinada especificidade, cederam espaço a uma aplicação interdisciplinar, contextualizada e problematizada em todos os seus aspectos com o objetivo de tornar o aluno consciente dos aspectos específicos e contextualizados da Química em toda a sua complexidade. 
Contudo, de acordo com dados empíricos pautados em relatos de professores, avaliações realizadas - como, por exemplo, o Exame Nacional do Ensino Médio (ENEM), mostra que os alunos não têm conseguido produzir respostas coerentes a partir de um conjunto de dados que exigem interpretação, leitura de tabelas, quadros e gráficos, e não conseguem fazer comparações ou fundamentar seus julgamentos e observações realizadas (OCN, 2006, p. 104) - e durante dois anos de iniciação à docência (PIBID), nota-se uma divergência realmente significativa em relação ao que se espera, de acordo com os documentos, e o que é observado na realidade do ensino médio.

Por fim, este projeto é apresentado com a intenção de constatar se essas observações estão de acordo com a realidade, isto é, se os alunos do ensino médio público brasileiro de uma escola de periferia estão desenvolvendo os estudos em química como os currículos oficiais objetivam que isso aconteça e qual é a perspectiva do aluno sobre a eficiência do processo. Os resultados em relação ao aprendizado técnico/contextualizado em química são preocupantes, contudo, a perspectiva do aluno acerca desta situação é ainda mais intrigante.

\section{OBJETIVOS}

Delimitou-se como objetivo desta proposta: (1) Identificar qual o nível de assimilação dos conteúdos ministrados em sala de aula pelos alunos do 3 o ano do ensino médio público nos três níveis de representação da Química (Microscópico, Macroscópico e Simbólico) de forma contextualizada através de um questionário subjetivo que visa extrair a concepção de cada aluno, com o seu vocabulário, em relação aos quatro aspectos citados (Macro, Micro, Simbólico e Contextualizado); (2) Comparar os resultados obtidos com o questionário aplicado com o que os documentos oficiais (PCN, PCN+, OCN e DCE-PR) esperam que os alunos assimilem através de uma Análise Textual Discursiva de ambos os documentos (questionário e diretrizes); (3) Identificar, através de uma nova ATD qual é a opinião dos alunos acerca dos resultados obtidos com as análises após o feedback.

\section{METODOLOGIA}

A pesquisa foi desenvolvida no Colégio Estadual Eurídes Brandão E.F.M.P., localizado no bairro Caiuá da cidade de Curitiba. Segundo a Secretaria de Estado da Educação do Paraná (SEED - PR), a instituição possui 100 alunos matriculados em seus terceiros anos no período da manhã. A proposta aqui apresentada teve como corpo de prova todos estes alunos.

Para melhor compreensão da metodologia, dividiu-se o desenvolvimento da proposta em quatro passos básicos, são eles: (1) Análise Textual Discursiva (ATD 01) dos documentos oficiais selecionados; (2) Coleta de dados técnicos e Análise Textual Discursiva destes (ATD - 02), (3) Feedback (F - ATD - 02); (4) Análise Textual Discursiva das cartas (ATD - 03); Em relação ao primeiro, após a aceitação do desenvolvimento da pesquisa pelo corpo estudantil e professores, foram analisados, através de uma ATD, os documentos oficiais citados nesta pesquisa ( $\mathrm{PCN}, \mathrm{PCN}+, \mathrm{OCN}$ e DCE-PR) visando extrair quais devem ser as competências e habilidades que um aluno do ensino médio deve desenvolver ao final de seus estudos em Química em todos os aspectos. Em seguida, foi apresentado aos alunos 
o resultado desta primeira análise, isto é, foi mostrado a eles o que é esperado que eles aprendam de acordo com os currículos na forma de uma aula expositiva dialogada. Após o primeiro passo, um questionário contendo três questões subjetivas que pretende extrair dos alunos tudo o que eles absorveram em química no ensino médio foi desenvolvido com base nos resultados da ATD-01 e aplicado às turmas de interesse.

Esses questionários foram analisados através de uma ATD (ATD-02), que teve seus resultados mensurados quantitativamente e qualitativamente em comparação com os eixos desenvolvidos com a ATD-01 dos documentos educacionais oficiais. No terceiro passo, foram apresentados os resultados referentes ao segundo passo aos alunos de forma dialogada, coletando, formalmente através de uma carta, suas justificativas acerca de seu desempenho. Também foi apresentada a oportunidade do aluno procurar uma orientação de estudo acerca da Química de acordo com o que foi apresentado por eles nas respostas dos questionários de forma individual e particular. Junto a isso, foram abertos momentos de reflexão acerca da organização e responsabilidade escolar: quais são seus objetivos, métodos, direitos e deveres.

A voz sempre foi passada aos alunos visando notar quais são suas perspectivas acerca da metodologia utilizada. Na quarta e última etapa foi realizada a Análise Textual Discursiva das cartas solicitadas no terceiro passo. Os parâmetros para a análise quantitativa do quarto passo foram determinados de acordo com o resultado da ATD-03.

\section{RESULTADOS E DISCUSSÃO}

\subsection{ANÁLISE TEXTUAL DISCURSIVA 01 (ATD - 01) DOS DOCUMENTOS OFICIAIS SELECIONADOS}

Analisando-se os documentos selecionados (PCN, PCN+, OCN, DCE-PR) notouse que estes apresentam várias perspectivas igualitárias acerca das metodologias e grade curricular de química. Destaca-se o aspecto histórico apresentado de forma interessante pelo DCE-PR (PARANÁ, 2008), onde são expostas várias possibilidades da contextualização histórica da química e da ciência no geral, junto a isso, a indicação presente no OCN (BRASIL, 2008) sobre a capacidade de abstração que deve ser também desenvolvida.

Segundo o DCE-PR e o OCN, apoiados pelo PCN + (BRASIL, 2002) e PCN (BRASIL, 1997), o estudo de química deve ser voltado ao desenvolvimento dos seguintes temas: transformações químicas, estudo das matérias e suas propriedades e modelos explicativos. Isto é, a tríade do ensino da química. A Figura 1 apresenta esta tríade de acordo com Mortimer, Machado e Romanelli (2000). Especificamente, como nota-se na Figura 2, de acordo com o DCE-PR (PARANÁ, 2008), deve ser bem estabelecido durante os três anos do ensino médio, ainda, dois campos além dos citados na tríade, porém, derivados dela, que são a Química Sintética e a Biogeoquímica e como estas derivam ou são manipuladas com o intuito de benefício ao desenvolvimento humano. 
Figura 1 - Tríade do ensino em química segundo o OCN.

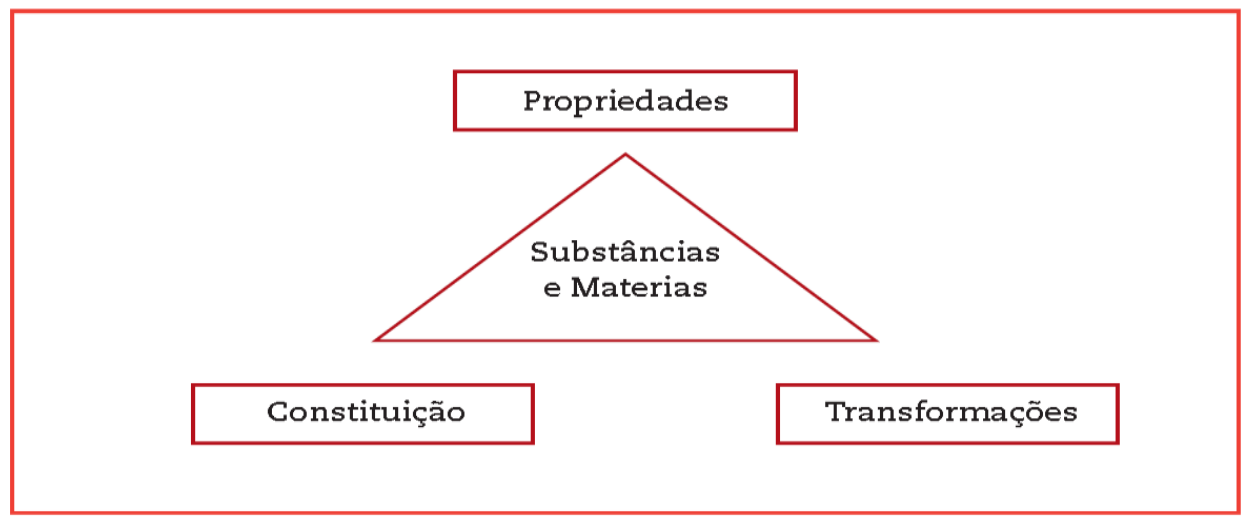

(Fonte: MORTIMER; MACHADO; ROMANELLI, 2000, p. 276)

Figura 2 - Objeto de estudo da química de acordo com DCE-PR.

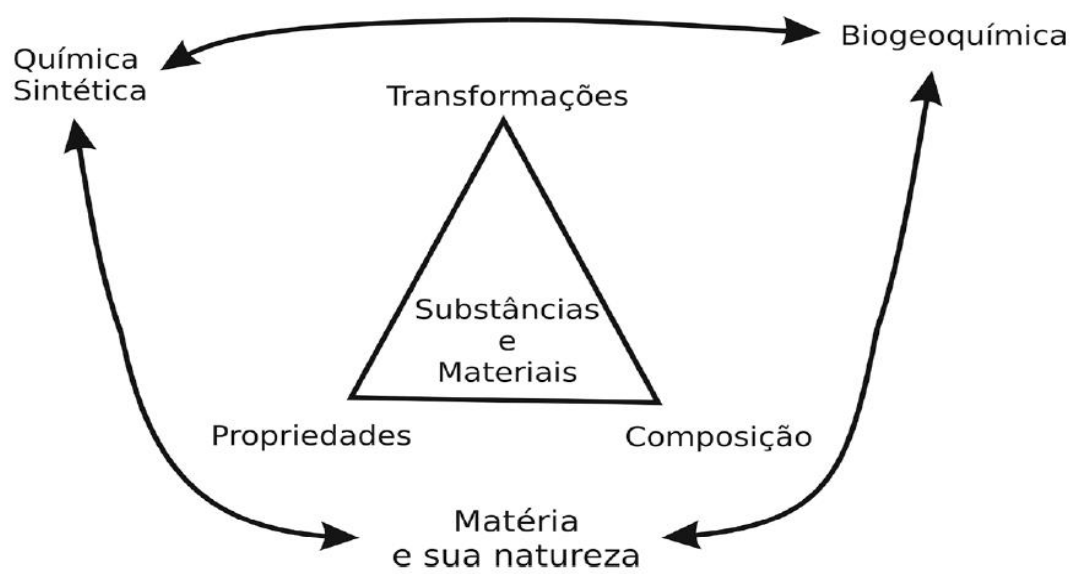

(Fonte: PARANÁ, 2008, p. 59).

Contudo, o simples "passar" destes conteúdos de modo metodista ou tecnicista, já não é o objetivo apresentado por estes documentos. Observa-se que tornaram-se prioridade quatro aspectos principais no ensino da química: (1) um ensino contextualizado, dinâmico e tecnológico, (2) que vise o desenvolvimento individual em contraponto a generalização (3) que respeite o conteúdo técnico de cada área, contudo, (4) que seja trabalhado de forma a dar aberturas a iniciativas interdisciplinares assegurando a mutabilidade e dinamicidade dos saberes científicos.

Em relação ao primeiro aspecto, ressalva-se que o ensino da química deve dar-se de forma que a apresente em toda a sua complexidade e história, de forma contextualizada, contudo, o contextualizar não se limita a simplesmente correlacionar os conceitos técnicos em sala de aula, e sim, problematizar sistêmica e individualmente estes, de forma a agregar à sala de aula, a história vivida pelo aluno. Junto a isso, o processo deve ser dinâmico para poder fomentar ferramentas para que se entenda a dinamicidade e complexidade do mundo atual, logo, a química deve ser trabalhada em seus quatro âmbitos de impacto: social, econômico, ambiental e político visando formar o cidadão consciente de seus direitos e deveres. Neste momento, tem-se nas mãos do professor, o papel importante de desmistificar a química. 
O segundo aspecto se refere ao estudo da singularidade em meio à heterogeneidade presente em sala de aula, isto é, respeitar cada nível de desenvolvimento cognitivo, visando extrair o máximo do potencial de cada discente cognitiva e afetivamente.

O terceiro aspecto assegura, de acordo ainda com os documentos, que não se deve, também, frisar somente os aspectos "não conteuditas" deve-se, primeiramente, desenvolver os conteúdos técnicos importantes para futuras compreensões.

O quarto aspecto refere-se ao desenvolvimento da percepção do aluno acerca de como se constrói o saber científico, isto é, não se fala somente em química pura e aplicada atualmente, vários são os conhecimentos requisitados de outras áreas para o desenvolvimento da química e vise-versa, neste momento, encontram-se abertas as portas para a interdisciplinaridade e desenvolvimento de projetos multidisciplinares. Junto a isso, deve-se tentar tornar o universo químico complexamente menor, tornando claro aos olhos do aluno como os saberes nesta área são mutáveis utilizando a história da química e da ciência no geral.

Por fim, após a análise geral destes documentos gerando as unitarizações fragmentadas expostas acima, desenvolveu-se quatro categorias básicas quais espera-se que o aluno se enquadre ao final de seus estudos de nível médio de acordo com as diretrizes, são elas: (1) Compreender a química em sua complexidade e história, (2) contextualizando-a com a sua realidade e problematizações sócio-políticas (3) estabelecendo conhecimentos capazes de relacionar a química em seus três âmbitos, além do contextualizado, de compreensão (macroscópico, microscópico e simbólico) sem a memorização de fórmulas e sim com o desenvolvimento do raciocínio lógico e compreensão de suas tecnologias e, por fim, (4) desenvolver crítica e filosoficamente a assimilação de conceitos técnicos práticos e teóricos acerca da química.

A partir disto, gera-se o novo emergente acerca do que foi apresentado, são eles: (A) espera-se que o aluno compreenda o papel da química na sociedade contemporânea, (B) interprete seus conceitos macro, micro e simbolicamente de forma lógica e coerente, (C) correlacione de forma fundamentada o que foi desenvolvido com o seu meio de vivência (D) apresente domínio sobre os termos técnicos da linguagem química, (E) desmistifique a química como "vilã" em relação à natureza, (F) compreendendo seus impactos políticos, sociais e ambientais tendo como base a história do seu desenvolvimento.

Logo, o questionário referido no Tópico 3 foi montado de acordo com os resultados obtidos na análise acima e os resultados obtidos com este questionário foram comparados com estes parâmetros acima desenvolvidos, contudo, para se referir aos resultados desta análise, estes serão chamados de R-ATD-01-X, Resultados da Análise Textual Discursiva número 01 onde " $X$ " representa a letra do parâmetro em questão. Portanto, um exemplo de aplicação desta terminologia, seria na comparação da resposta de um aluno ao questionário que compreende o papel da química na sociedade atual, a resposta deste aluno corresponde ao parâmetro R-ATD-01-A. 


\subsection{COLETA DE DADOS TÉCNICOS, ANÁLISE TEXTUAL DISCURSIVA 02 (ATD - 02) E FEEDBACK}

Como indicado no tópico anterior, o questionário foi montado de acordo com os R-ATD-01-X, logo, foram montadas 03 (três) questões para a coleta de dados, são elas: (1) escreva, com as suas palavras, tudo o que você acredita que a química esteja ligada com a sociedade atual e explique como ocorre essa ligação, (2) escreva tudo o que você sabe sobre Química Geral e Inorgânica, explique os conceitos que você citar e os correlacione com o seu cotidiano ou qualquer outro aspecto econômico, social e/ou ambiental sempre que for possível e (3) escreva tudo o que você sabe sobre Química Orgânica, explique os conceitos que você citar e os correlacione com o seu cotidiano ou qualquer outro aspecto econômico, social e/ou ambiental sempre que for possível.

No total, foram obtidos 72 questionários respondidos dos 100 previstos na projeção metodológica. Analisando-se quantitativamente as respostas apresentadas as três questões acima, notou-se que, além dos parâmetros apresentados na conclusão do Tópico 4.1 (R-ATD-01-A,B,C,D,E,F), para o enquadramento de todas as respostas, foi necessária a criação de quatro categorias emergentes adicionais, são elas: (a) número de alunos que citaram superficialmente um pressuposto teórico sem fundamentação concisa, (b) número de alunos que definiram a química orgânica como sendo intrinsecamente natural e com o objetivo de restaurar o impacto ambiental, (c) número de alunos que definiram a química inorgânica como aquela que é sintética e prejudicial ao meio ambiente e (d) número de alunos que apresentam determinada confusão teórica.

Para fins didáticos, este novo emergente será denominado de R-ATD-02-X, onde $\mathrm{X}$ representa o emergente adicional correspondente $(a, b, c, d)$. Portanto, as respostas encontradas no questionário foram analisadas quantitativamente por dois viés: (1) respostas que correspondem aos parâmetros dos documentos oficiais (R-ATD-01-X) e (2) resultado que correspondem aos R-ATD-02-X e se enquadram nos novos emergentes adicionais apresentados acima. Logo, após segregação dos resultados, apresenta-se, no Gráfico 1, a análise quantitativa das respostas que correspondem aos parâmetros dos documentos oficiais. Em relação ao segundo resultado (que não correspondem ao esperado pelos parâmetros R-ATD-01-X), apresenta-se o Gráfico 2.

Gráfico 1 - Análise quantitativa de respostas que correspondem aos parâmetros R-ATD01-X.

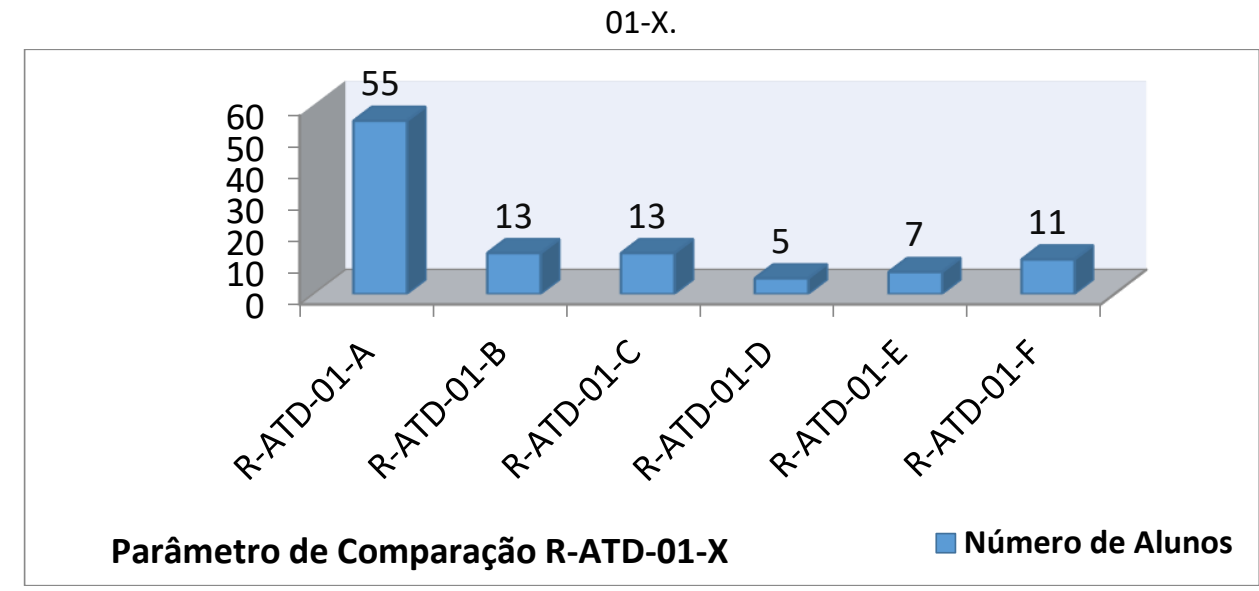

(Fonte: O AUTOR, 2016) 
Gráfico 2 - Análise quantitativa de respostas que correspondem aos parâmetros R-ATD02-X.

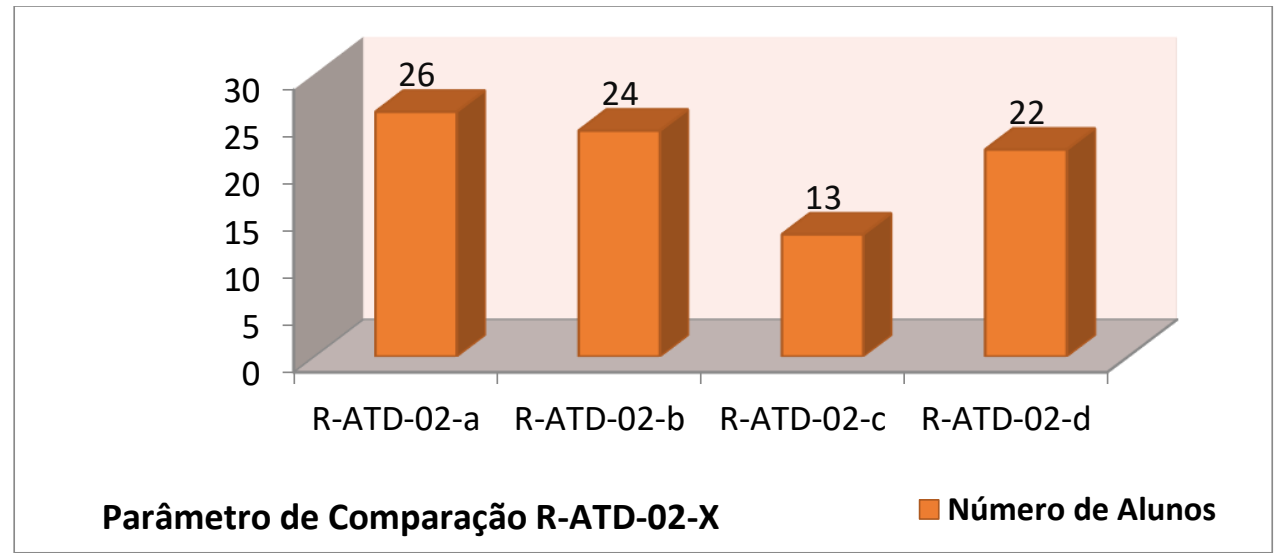

(Fonte: O AUTOR, 2016)

Observa-se de acordo com o Gráfico 1 que, uma grande porcentagem (76\%) dos alunos conseguem informar onde a química se encontra na sociedade atual ( $R$ ATD-01-A), como exemplifica a seguinte citação: "a química, para mim, está ligada em tudo na sociedade e no mundo, desde objetos, alimentação ou o ar que respiramos, em tudo temos ligações de dois ou mais elementos para formar produtos, ou coisas do meio ambiente que se formam sozinhas", contudo, somente (18\%) conseguiram desenvolver uma explicação teórica coerente acerca de como se encontra os saberes técnicos químicos, dominando sua linguagem (18\%) (RATD-01-B,D), por exemplo: "em processos gerais e inorgânicos eu lembro que aprendi sobre uma escala de $\mathrm{pH}$ de ácidos e bases, onde quanto mais negativo, mais ácido é, e quanto mais positivo (acima de 7) mais base é, tendo como neutro, o $\mathrm{pH}$ da água, que é igual a 7".

Em relação ao parâmetro R-ATD-01-C este número reduziu-se à 7\%, pode-se citar o seguinte exemplo: "[...]aqui perto de mim, tem a (empresa do ramo de cosméticos), fábrica de remédios, onde se usa muito os processos químicos". Junto a isso, poucos foram os alunos (15\%) que desenvolveram a química historicamente atrelando o seu desenvolvimento com impactos políticos, ambientais e econômicos citando a sua história (R-ATD-01-F), a citação a seguir exemplifica: " $a$ química geral, por exemplo, é aquela que estuda os modelos atômicos, começando lá com Demócrito, passando por Thompson, Rutherford e Bohr, que revolucionaram a maneira de ver o mundo impactando em sua época" ou "[...] o desenvolvimento de modelos atômicos ajudou no desenvolvimento de tecnologias que hoje são fundamentais para o desenvolvimento do ser humano".

Também uma pequena porcentagem de estudantes (10\%) conceituou a química, de forma coerente, como uma não "vilã" (R-ATD-01-E) com a natureza de forma explicita ou implícita, por exemplo: "[...] hoje em dia, o mundo está poluído , com o ar ruim, ai entra a química para tentar melhorar isso". Portanto, nota-se uma dificuldade por parte do estudante de associar concretamente os conceitos teóricos da química com o seu dia-a-dia, e, o que é mais preocupante, com seus impactos políticos e sociais de acordo com a sua história. $\mathrm{O}$ que fere a proposta apresentada pelos DCE-PR, por exemplo.

Analisando-se agora o Gráfico 2, é possível observar que uma grande fundamentação teórica concisa) souberam citar, por mais que superficialmente, o 
que cada subdivisão de ensino da química aborda (R-ATD-02-a). Por exemplo, um dos alunos ao responder a questão 02 citou: "[...] a química geral é aquela que estuda os modelos atômicos, e a inorgânica os sais, bases e ácidos" ou, uma resposta a questão 03 "[...] a química orgânica é aquela que estuda a nomenclatura dos compostos que tem carbono". Isto é, não fundamentaram tecnicamente pelo menos um dos temas citados.

Outro ponto de interesse, é o parâmetro R-ATD-02-b onde 33\% dos alunos citaram que o papel da química orgânica é ofertar uma "vida melhor" e "sem poluentes", como mostra as seguintes afirmativas: "ao contrário da química inorgânica, a química orgânica tem o objetivo de não poluir e ajudar o ambiente mexendo com coisas que são retiradas da natureza" ou "a química orgânica é aquela que ajuda o ambiente sem usar poluentes, como os plásticos".

Junto a este aspecto, os alunos que denominaram a química inorgânica no sentido oposto ao do orgânico citado acima (R-ATD-02-C) (18\%), as seguintes afirmativas exemplificam: "a química inorgânica é aquela criada pelo homem e que polui o meio ambiente", "a química inorgânica mexe com aquilo que é sintético como o NaCl." ou "a química inorgânica são compostos que não estão ligados diretamente com o meio ambiente, alguns compostos podem causar degradação da natureza, mas não todos, como o NaCl".

Por fim, um total de $31 \%$ dos estudantes apresentaram determinada confusão teórica (R-ATD-02-d) ao responder o questionário, isto é, citou superficialmente os conceitos, contudo, no momento de os desenvolver designou medidas errôneas, como exemplificam as citações a seguir: "a química orgânica está relacionada ao carbono, ajuda a diminuir os combates ao meio ambiente, não utiliza materiais químicos"ou "a química geral, ela não aborda tudo mas sim resolução de contas, por exemplo, a distribuição eletrônica de elétrons do elemento".

Esta discrepância entre realidade e currículo pode ser observada, também, em outros âmbitos e especificidades. Carvalho (2014) ao comparar como se desenvolvia o ensino de reações químicas, perguntas realizadas pelos alunos e os livros didáticos com os documentos educacionais oficias, notou que os livros didáticos fornecem o apoio necessário para o desenvolvimento do conteúdo, porém, não de forma plena, sendo então, o professor responsável por conexões mais profundas de acordo com os parâmetros oficiais.

O trabalho de Souza (2009) também contempla essa perspectiva entre os currículos e realidade no âmbito da educação física, e observa que a prática estudada no ambiente de graduação e apoiada pelos documentos educacionais oficiais, muitas vezes, cedem lugar a metodologias corriqueiras e sem o embasamento teórico necessário com o intuito de favorecer a praticidade.

Depois de firmadas estas conclusões, iniciou-se o feedback aos alunos, onde foi solicitada, em forma de carta, que dissertassem acerca da problemática levantada, "por quê há essa diferença (ou semelhança no caso de proximidade com os documentos) entre os currículos e o que nós apresentamos no questionário? qual a minha opinião?". Foi observado, informalmente, que, no início do feedback, a postura tomada pelos alunos era de transferência de culpa para terceiros como: o organismos escolar, professor, pais e mães, governo etc., contudo, conforme a discussão foi ganhando profundidade, deu-se espaço para determinadas autocríticas que serão discutidas no tópico 4.3. 


\subsection{ANÁLISE TEXTUAL DISCURSIVA DAS CARTAS (ATD - 03)}

Após o feedback e o recolhimento das cartas, deu-se início a ATD-03. 0 número de cartas recolhidas foi de 51 cartas ( $71 \%$ do número total de participantes inicias (que responderam o questionário)). Das cartas analisadas, nenhum aluno considerou seu desempenho como satisfatório e somente justificaram seu "baixo" desempenho (medida que auto julgaram, pois em nenhum momento foi exposto o desempenho individual se não solicitado de forma particular).

Logo, o resultado da ATD gerou os seguintes parâmetros de análise quantitativa: qual o número de alunos que justificaram seu desempenho (A) pelos recursos quais a escola possui, (B) pela falta de aulas mais dinâmicas, (C) por interferências comportamentais como o comportamento indevido dos colegas, (D) pela falta de tempo de aula, (E) pela dificuldade dos conteúdos ministrados, (F) pelo déficit provindo de professores anteriores ao atual e (G) por determinado aspecto pessoal como falta de interesse ou dificuldades extraclasse. Para fins metodológicos, os parâmetros resultantes desta ATD serão designados por R-ATD03-X onde X significa o parâmetro em questão (A, B, C, D, E, F, G).

O Gráfico 3 apresenta os resultados desta análise. Em relação ao parâmetro R-ATD-03-A, é observado que cerca de $22 \%$ dos alunos considera os recursos da instituição de ensino insuficiente para auxiliá-los no aprendizado de química, por exemplo: "química é uma matéria fácil, mas acho que faltam recursos na escola, como laboratórios", "No colégio, deveriam disponibilizar materiais, sala de laboratório"ou "Na minha opinião, a química não é uma matéria difícil, mas com os recursos que temos na escola fica meio complicado". Na realidade, apesar da instituição apresentar espaço físico para o desenvolvimento de aulas mais dinâmicas, o laboratório, por exemplo, nunca foi utilizado, segundo os alunos.

O parâmetro R-ATD-03-B corresponde a um total de $37 \%$ das citações, por exemplo: "precisamos de mais aulas práticas para entender mais o assunto"ou "deviriam haver mais aulas práticas de química, oficinas, enfim, propostas mais dinâmicas". Em relação ao R-ATD-03-C, 14\% dos alunos citaram em suas cartas, como exemplo, tem-se: "Na nossa turma os alunos são muito agitados $e$ isso impede que o professor explique". O parâmetro R-ATD-03-D foi apresentado em $10 \%$ das cartas, um exemplo é o seguinte: "O tempo de aula é muito curto, até $o$ professor arrumar a sala, os alunos ficarem em silencio, demora muito, e este é um tempo de aula perdido".

O eixo R-ATD-03-E mostra que $31 \%$ afirmaram que o conteúdo de química ministrado é muito complicado, como modelo, tem-se: "a química se torna difícil por ter muito conteúdo e ter muita matemática". Cerca de $37 \%$ dos alunos citaram o parâmetro R-ATD-03-F, como exemplo de citação tem-se o seguinte: "fui mal no questionário pois nos outros anos tive professores que não explicavam bem e eu não entendia quase nada da matéria". Por fim, nota-se que o aspecto mais ressaltado pelos alunos é o R-ATD-03-G (80\%), ou seja, a grande maioria dos alunos assumiu a responsabilidade pelo seu desempenho no questionário, atrelando, também, fatores secundários extraclasse, a citação seguinte representa este parâmetro: "Sei que a culpa não é só do professor, reconheço que ultimamente não tenho demonstrado muito interesse e esforço para entender essa matéria [...]"ou, no caso de fatores extra sala de aula "[...] a minha mãe fala que eu vou mal pois de manhã eu não como, e não comer faz você perder a atenção e faz mal para a saúde". 
Gráfico 3 - Análise quantitativa das cartas que correspondem aos parâmetros R-ATD-03$\mathrm{X}$.

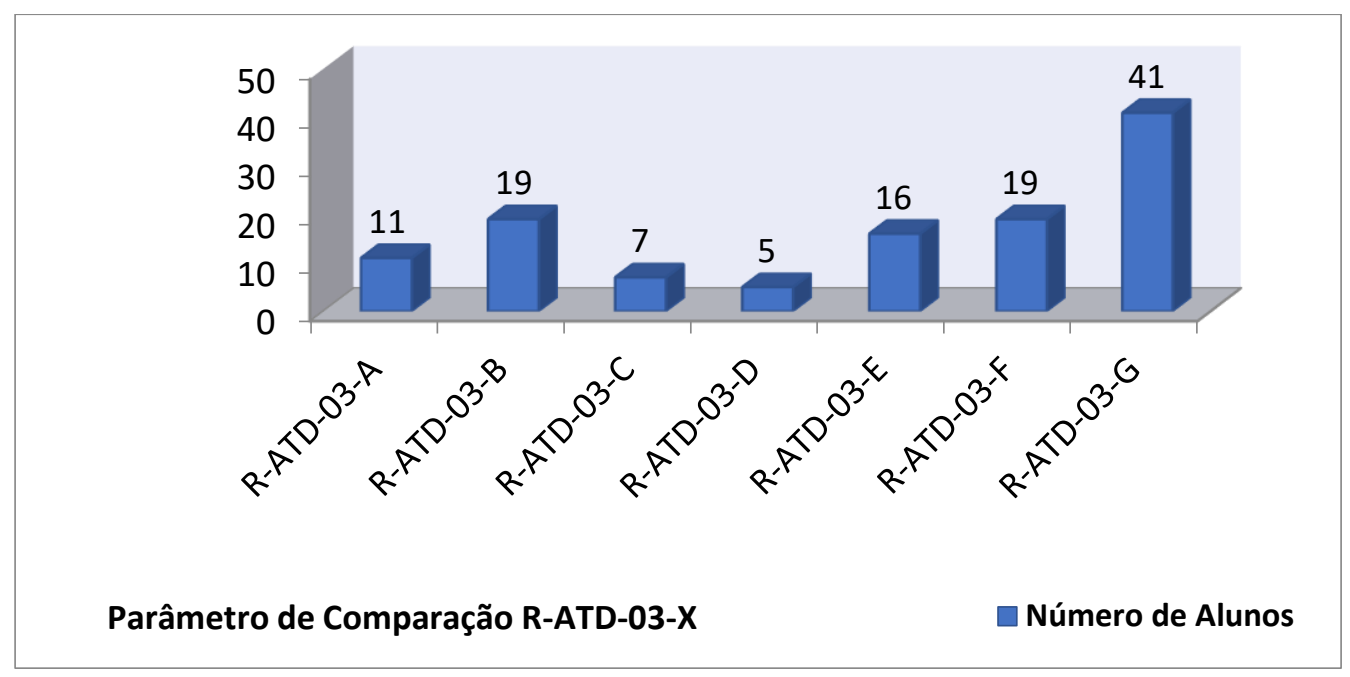

(Fonte: O AUTOR, 2016)

\section{CONSIDERAÇÕES FINAIS}

Portanto, pode-se concluir que, nesta realidade observada, os documentos oficiais educacionais são atendidos parcialmente, isto é, os aspectos de entendimento social da química apresentam-se bem desenvolvidos, contudo, aspectos técnicos e problematizados que produzam um aprendizado significativo estão sendo menos priorizados.

Junto a isso, a falta de dinamicidade dos conteúdos ministrados está sendo prejudicial segundo a análise dos próprios alunos. Isto é, fixou-se demais os aspectos acerca da "contextualização" no ensino de química, que se mostrou um ensino mais uma vez fragmentado e sem impacto a longo prazo para o aluno, sendo que os documentos já vigoram a, pelo menos, oito anos. Ainda, pode-se atribuir à "contextualização" aqui tratada uma característica mais correlativa do que a de contextualizar profundamente um conteúdo, logo que uma grande porcentagem dos alunos sabem que processos químicos estão presentes na sociedade atual, e qual o seu papel, porém, não sabem assegurar como estes foram desenvolvido historicamente e quais são as suas concepções teóricas.

Porém, é interessante observar que, de acordo com os próprios alunos, não somente o professor ou a instituição de ensino são culpados pelos resultados aqui apresentados, e sim, eles possuem uma parcela significativa de culpa neste contexto.

Por fim, é cedo e incabível a generalização desses dados para demais realidades, casos particulares tem resultados particulares, contudo, observa-se que nesta realidade, aulas mais dinâmicas, contextualizadas de forma a desenvolver a cidadania e firme tecnicamente, com abordagens mais concretas sobre o desenvolvimento da ciência e suas características, como a mutabilidade, devem ser urgentemente desenvolvidas, visando à formação de um cidadão completo, ciente de seus direitos e capaz de discutir sobre eles, agora, com o aspecto técnico básico da química. 


\title{
REALITY AND OFICIAL GUIDELINES OF EDUCATION IN CHEMISTRY : WHAT IS THE DISTANCE ?
}

\begin{abstract}
After analyzing the official documents that guide and ensure the methodological quality of education in the country, make it clear what should be the ideas which a high school student must master in relation to chemistry after completion, or near it, their studies. That is, memorizing formulas and guided repetitions in symbolic references aimed at teaching particular specificity, gave way to an interdisciplinary application, contextualized and problematized in all its aspects in order to make the student aware of the specific aspects and contextualized chemistry in all its complexity. However, according to empirical data guided by teacher reports and observations made during two years of initiation to teaching (PIBID), there is a truly significant divergence from the expected, according to the documents, and what is seen in high school reality. Finally, this project is the idea to see if these observations are in line with reality, that is, if students in the average Brazilian public education in the periphery of school are developing studies in chemistry as the official curricula aim that happen and what is the student's perspective on the process efficiency. The results in relation to technical learning / contextualized in chemistry are worrying, however, the student's perspective on this situation is even more intriguing.
\end{abstract}

KEYWORDS: Education in chemistry. Curriculum and reality. Efficiency teaching and learning. Curriculum in chemistry. 


\section{REFERÊNCIAS}

BRASIL, SEB, Ministério da Educação: Parâmetros Curriculares Nacionais: Ciências da Natureza, Matemática e suas Tecnologias. Brasília: MEC, 1997. Disponível em:< http://portal.mec.gov.br/seb/arquivos/pdf/ciencian.pdf $>$. Acesso em: 24 fev. 2017.

BRASIL, MEC. Orientações Curriculares Complementares aos parâmetros curriculares nacionais: ciências da natureza, Matemática e suas tecnologias. PCN+. Brasília: MEC, 2002. Disponível em:< http://portal.mec.gov.br/seb/arquivos/pdf/CienciasNatureza.pdf>. Acesso em: 24 fev. 2017.

BRASIL, MEC. Orientações Curriculares para o Ensino Médio: ciências da natureza, Matemática e suas tecnologias. Brasília: MEC, 2006. Disponível em:< http://portal.mec.gov.br/seb/arquivos/pdf/book volume 02 internet.pdf $>$. Acesso em 24 fev. 2017.

CARVALHO, J.G.N. As perguntas dos estudantes sobre reações químicas, os livros didáticos e os documentos educacionais oficiais: uma análise comparativa e compreensiva. Porto Alegre, 82 p., 2014. Dissertação (Mestrado). - Pontifícia Universidade Católica do Rio Grande do Sul. Disponível em:< http://repositorio.pucrs.br/dspace/handle/10923/6798>. Acesso em: $24 \mathrm{fev}$. 2017.

MORAES, R; GALIAZZI, M. C. Análise textual discursiva: processo construído de múltiplas faces. Ciência \& Educação, v.12, n.1, p.117-128, 2006. Disponível em:< http://www.scielo.br/pdf/ciedu/v12n1/08.pdf>. Acesso em: 24 fev. 2017.

MORAES, R. Uma tempestade de luz: a compreensão possibilitada pela análise textual discursiva. Ciência \& Educação, v.9, n. 2, p.191-211, 2003. Disponível em: $<$ http://www.scielo.br/scielo.php?script=sci arttext\&pid=S151673132003000200004>. Acesso em: 24 fev. 2017.

MORTIMER, E. F.; MACHADO, A. H.; ROMANELLI, L. I. A proposta curricular de química do estado de Minas Gerais: fundamentos e pressupostos. Química Nova, v. 23 , n. 2, p. 273-83, 2000. Disponível em:< http://www.scielo.br/pdf/qn/v23n2/2131.pdf>. Acesso em: 24 fev. 2017.

PARANÁ, DEB, Secretaria de Estado da Educação: Diretrizes Curriculares Estaduais da Educação Básica: Química. Paraná: SEED, 2008. Disponível em:< http://www.educadores.diaadia.pr.gov.br/arquivos/File/diretrizes/dce quim.pdf >. Acesso em: 24 fev. 2017. 
SOUZA, S.E.D. A prática pedagógica e o ensino de Educação Física no cotidiano de duas escolas públicas estaduais do bairro Jardim Santo André: entre o texto oficial e o cotidiano. São Paulo, 130 p., 2009. Dissertação (Mestrado) - Pontifícia Universidade Católica de São Paulo.

TABA, H. Elaboración del currículo. Buenos Aires: Troquel, 1974.

DOI: $10.3895 /$ rbect.v10n1.5689

Como citar: LIMA, R. R. J.; SILVA, R. P.; GBUR, D. S.; BARBOZA, M. M.; COSTA, L. C. S. Realidade e Diretrizes Oficiais da Educação em Química: Qual é a Distância? Revista Brasileira de Ensino de Ciência e Tecnologia, v. 10, n. 1, 2017. Disponível em: <https://revistas.utfpr.edu.br/rbect/article/view/5689>. Acesso em:xxx

Direito autoral: Este artigo está licenciado sob os termos da Licença Creative Commons-Atribuição 4.0 Internacional. 